\title{
Chinese Philosophy, "Postcomparative" Approaches and Transcultural Studies: A Reply to Vytis Silius
}

\author{
Jana S. ROŠKER*
}

In the previous issue of Asian Studies (May 2020), Vytis Silius published a paper entitled Diversifying Academic Philosophy: The Post-Comparative Turn and Transculturalism, in which he dealt with some basic, significant and hitherto still unsolved questions regarding the so-called "post-comparative shift" in Chinese and intercultural philosophy (see Silius 2020). The paper is well written, topical and very relevant. In spite (or all the more because) of the fact that it contains some controversial issues, it represents an important contribution to the present debates in the field. In this light, I would like to challenge the author (and his readers) by addressing the following issues, with which I aim to expose some of the minor problems contained in the paper on the one hand, but also propose some further general considerations of the delineated problems, on the other.

In the first part of the paper, the author provides a very thorough and coherent critique of the Eurocentric and Orientalist nature of Western philosophy, especially regarding its current institutionalisation and historical consolidation. He explains why he does not think that the various discriminatory tendencies and attitudes within the Western academic institutions against the inclusion of non-Western discourses are racist, but rather a result of "inertia". I am not sure what might actually be the qualitative difference between "stubborn racism" and "inertia", which is usually defined as a tendency to do nothing or to remain unchanged. First of all, racism is not something limited to a "stubborn" (and, hence, voluntary) maintenance. It is an inherent, almost essential part of the very discourse of Western philosophy, which relies on the reality of the concept of "race" as a "substance", that is, among other, characterized by determinism, hypostatization, and reification, and rooted in a paradigm in which the being precedes the becoming (Xiang 2019, 2). And secondly, inertia is a tendency to do nothing about a current state of affairs; it is a mechanistic, non-reflective and uncritical attitude, which lacks any kind of autonomy, and is conservative

Jana S. ROŠKER, Professor of Sinology, Department of Asian Studies, Faculty of Arts, University of Ljubljana.

Email address: jana.rosker@ff.uni-lj.si




by its very nature. In this sense, inertia (of racism) is by no means better than a "stubborn racism" would be, for they both can, in principle, contribute equally to the continuation of racism, which is still present in academic institutions. I guess that what Vytis Silius tried to say in this respect was that the present situation is not a consequence of ideologically manifest and consciously implemented discrimination, but rather a result of the non-reflective and unconscious preservation of racism. However, a latent (and unconscious) racism might be even more dangerous (and more persistent) than a conscious one, for (almost) no educated person would nowadays still openly advocate racism. Hence, these latent forms of racism (which manifest themselves in what the author calls "inertia") are, in fact, even more harmful precisely because they are difficult to grasp, to point out, and hence to fight against. This difference between manifest and latent racism is structurally linked to Said's notions of the relation between latent and manifest Orientalism (see Said 1979, 206ff).

Already in the abstract, the author exposes a rather bold supposition, according to which "universal knowledge, i.e. a knowledge which transcends cultural particularities" belongs to the elementary tasks (or tenets) of philosophy. This supposition belongs to the fundamental, however little questioned or proven basis of Silius' argumentation; in other words, it belongs to the central common threads of the entire paper. In my view, this assumption is rather problematic, since the question of the possible existence (let alone the function) of "universal knowledge" has never really been clarified. It is of course true that, as the author points out, "one of widely held agreements is that all types of philosophy strive for a universal type of knowledge" (Silius 2020,261). It certainly holds true that in their work most philosophers and scholars of philosophy aim to generate universally valid insights. However, these are not necessarily "universal types of knowledge", since they do not pertain to one single, all-embracing universal knowledge, but rather to forms and types of knowledge which can be constructed and created within particular disciplines, methodologies or paradigms. Can we really think of knowledge (or philosophy) completely separated from the particular discrete culture in which it was created? ${ }^{1}$ Is this, on the other hand, truly something we should wish for?

Later on in this paper, Vytis Silius tries to relativize such a notion of universalism by complementing (or additionally explaining) it with Rein Raud's idea, according to which philosophy seeks "to clarify the nature of things on the most abstract

1 Besides, in this regard we can also not forget the element of subjectivity. Philosophy is always the product of human beings. And, can we really think--even in pure theory-of an isolated, universal human being, without her embeddedness in a concrete language, discrete experiences, histories, narratives and biographies? 
level" (Raud 2006, 621). Particularly due to the fact that we are dealing here with Chinese philosophy, it is even easier to see the problematic nature of such a claim. As we all know, Chinese philosophical traditions are rooted in the paradigm of immanent transcendence ${ }^{2}$ or the so-called one-world-view. Due to the dynamic paradigms in which they were developed, they do not establish fixed and static boundaries between the concrete (empirical) and the abstract (rational) notions. This implies that not only the general idea of universality, but even its somewhat relativized form of "clarifying the nature of things on the most abstract level" would necessarily exclude traditional Chinese philosophy from such a notion of universal or general philosophy.

Hence, if we could agree with this definition, we would necessarily be forced to exclude most of the Chinese philosophical traditions from a "universal philosophy", except for its rare parts that could be interpreted through the lens of "clarifying its objects on the most abstract level".

It seems as though Vytis Silius is somehow aware of the inadequacy of pure universalism, for he is repeatedly trying to mitigate the notion. However, in spite of all such attempts to relativize the idea of the "universal thrust", the problem itself still remains open: the very concept of universal knowledge is, even when based upon some (not sufficiently clarified) modes of relativity, still an abstraction that is very much alien precisely to immanent traditions like the Chinese one. Hence, such a "striving for universality" is, in itself, an essentially Western idea. It is an idea that is alien and in contradiction with the basic paradigms defining Chinese philosophies, for it can only be established in the framework of a philosophy of transcendence, which is, above all, trapped into a static and unchangeable framework of eternal validity. In this respect, we should definitely ask ourselves whether by advocating a seemingly "democratic" idea of a universal philosophy, one is not reproducing the same old patterns of discrimination that have enabled or led to the exclusion of all non-Western forms of thought from the "sacred realm" of philosophy?

Nevertheless, it is certainly true that the structure of the relation between universality and particularity belongs to the core issues which lie at the very grounds

2 From the viewpoint of Western philosophies, this notion is controversial and problematic in itself, since in the referential frameworks that prevailed in the Euro-American intellectual traditions, transcendence and immanence exclude one another. However, in the dynamic methodological framework of traditional Chinese philosophies, this is not necessarily the case. Nevertheless, in order to avoid possible misunderstandings, it might be better to choose another, less controversial term to express this idea. Here, we could point to the concept of the one-world-view, or rather describe it as a model that is similar to the pantheistic form of transcendence in immanence. 
of the current search for genuine intercultural philosophical inquiry. ${ }^{3}$ Precisely because of this reason, we should even more eagerly strive to liberate it from the realm of standardized universalism. In this context, Silius attempts to propose a different understanding of philosophy, namely as "knowledge that incorporates contingencies into the bigger picture". This is a proposition which obviously argues for the implementation of deductive approaches, and has hence to be seen in connection with Silius' advocating the more intensive inclusion of empirical sciences into contemporary "postcomparative" transcultural methods of intercultural philosophical work, an issue that will be shortly elaborated upon later in this text.

In my view, our treating of the relation between universalism and particularism should not remain limited to induction and deduction, respectively, even though the two methods are (much too often) seen as the two allegedly only possible, and hence exclusive, forms of structuring this relation. In this respect, we need to seek a form that would allow for an easier and smoother inclusion of traditional Chinese philosophy (as one of the contingent discourses) into the relation between contingencies and the "bigger picture". I believe that regarding intercultural (and especially transcultural) philosophy, the relation between universality and particularity should be based upon the principle of dynamic complementarity.

Let me exemplify this issue by an analogy with the inseparable connection between language and thought: although the ability or the potential to create language and thus linguistic communication is universal, each individual language and the grammatical structures by which it is defined are culturally conditioned. Langue and parole do not refer to the same linguistic entity. The same holds true for philosophy as a general system of thought which opens and develops "questions of deep human concern while proving the ideas they contain with rational arguments" (Defoort 2001, 403) on the one hand, and Chinese philosophy as a specific "type or genre" (ibid.) of philosophy with a specific, unique methodol$\mathrm{ogy}^{4}$ on the other. As with all philosophies, it is a form of human thought. In other words, like all other philosophies, Chinese philosophy has also arisen from the essential human need to philosophize. This need or this feature of human

3 Even the so-called "post-comparative turn", (provided, of course, that we can truly denote Hans Georg Moeller's critical analysis of the current state of intercultural philosophy as a post-comparative "turn"), an idea that is highly praised by the author, in fact chiefly proposes nothing else than precisely a restructuring of the very relation between universality and particularity.

4 Thus the expression "Chinese philosophy" does not refer to a geographic dimension of this universal term, but is rather an expression of the cultural conditionality which defines a certain form of philosophizing, or of a certain system of philosophical thought with a typical paradigmatic structure. 
thought and sentiment is something universal, precisely the same as the human ability to generate language.

I think we all agree that the exclusive establishment of a universal, overall valid language would not only kill off all other manifold ways of understanding, expressing and interpreting reality, but also reduce the latter to only one, monolithic linguistic construction of the world. In a similar manner, a construction of "universal philosophic truths" would (in spite of its comfortable and comforting nature) likewise impoverish our manifold, innumerable ways of understanding reality.

But just as there can be no langue without parole (and vice versa), because they are interdependent and continuously enrich and complete one another, the relation between general and particular philosophies should also be seen as complementary and co-relative, similar to the Chinese binary category of ben 本 and mo 末. ${ }^{5}$

Hence, trying to squeeze the two oppositional notions into a relation that is evaluated exclusively by induction or deduction is rather inadequate. If we operate with induction, i.e. if we conclude from (well-known) particularities to the existence of an universality, our analysis will necessarily result in a conclusion which determines the predominant position of a certain particular philosophical approach. In other words: we universalize a certain kind of particular approach, which then automatically serves as the only valid reference point for evaluating all existing particularities. All traditional Eurocentric prejudices regarding the value (and the very existence) of all non-European philosophies were constructed in this way.

Vytis Silius is well aware of such problematic biases and attempts to correct them by proposing a deductive mode of universal and particular philosophical systems. He suggests avoiding the weakness of the alleged universalism described above, which, in reality, is nothing but a "Eurocentric hegemony posing as universalism" (Silius 2020, 262), by surpassing the existing isolation of philosophy from the empirical sciences, which currently prevails in universities. He criticizes the fact that at Western academic institutions philosophy is being taught as a discourse in which the empirical data is not respected enough, for it is often subordinated to the neat systemic "grand picture" of "pure" philosophy. However, in my view, such subordination is not necessarily a flaw. Firstly, empirical data is (as Silius himself

5 For those readers who are not familiar with Chinese philosophy or Sinology, let me explain the basic nature of this traditional Chinese binary category: in short, the term ben refers to the elementary, common root (the universal threat) of any entity, whereas mo denotes the manifold specific, discrete branches (particularities) arising from it. Unlike the Hegelian model, in which the root of a plant is in contradiction with its stem, which negates it, the characteristic nature of this binary-oppositional pair is complementary, since the root (ben) without branches $(m o)$ is dead, while the latter can neither exist without the former. 
rightly recognizes) not always objectively reliable, just as the notion of objectivity itself is questionable. The problem would occur in cases when they would be ignored or even falsified by pure speculations, as is for instance the case with some dogmatic and monotheistic theologies. It is, to be sure, not too good if the "grand picture" of rational speculation is in open contradiction with the collected data. However, it is equally questionable whether it would be reasonable to take empirical data as a basis of the rational model. ${ }^{6}$ Indeed, this is a question that needs to be clarified in the future development of global philosophy or philosophy "as such". Its overall complexity includes the general question about the relation between empirical and rational methodologies, and hence it demands a wide and interdisciplinary debate. ${ }^{7}$ Therefore, it is a bit too early, in my view, to criticize the "subordination" of the empirical data to philosophy. Philosophy is speculative by nature, and the elimination of its rationality (or its complete dependence on empirical data) would imply the end of philosophy as an academic discipline, for it would, in fact, become redundant. But on the other hand, it is quite clear that empirical and philosophical sciences have to cooperate in order to obtain relevant new knowledge that could really have some significance for the contemporary world. However, the empirical sciences mostly do not take into account philosophical insights, and if they do, then they always treat these as elements that are subordinated to their own paradigmatic network. And I think by doing so, they are acting sensibly and in their own right, as it is equally right for philosophy to subordinate to its own rational work the results of empirical investigations. When criticizing traditional philosophy in this respect, Silius also claims that "the respect for data is much more binding in other academic disciplines of the humanities and social sciences" (ibid., 263). Here, we must ask ourselves which humanities exactly he has in mind, notwithstanding the fact that social sciences are, to a great extent (maybe with the only exception of the sociology of culture), empirical by nature anyway. In this context, he also mentions that "psychologists, anthropologists, sociologists are more confined by empirical data" (ibid., 262), which is of course true. However, we have to point out that all these disciplines are, to a great extent, likewise empirical sciences. Two rather explanatory examples of academic, highly theoretical disciplines, which truly belong to humanities, are, for instance, literary and aesthetic theories. Do such disciplines, for instance, have to accept hard-core empirical data in order to be seen as sciences in the sense of

6 The vast majority of the sub-disciplines of mathematics, which is, in its essence, also a rational science, are likewise completely separated from the empirical data; however, nobody finds it necessary to question such a basic framework of mathematics.

7 A very interesting and promising starting point for such debates could be provided, for instance, by applying in this context Li Zehou's notion of "transforming empirical into the transcendental" (Rošker 2020, 182). 
Wissenschaft? All these questions relate to the problem of the relation (or proportion) between subjectivity and objectivity and to our basic understanding of humanities as such, as well as their true significance and value. This does not imply, however, that philosophy as a discipline could not (or should not) enter a fruitful interrelation with empirical sciences: albeit it is, as mentioned above, a speculative science at its very heart, philosophy as such is also not a monolithic construction, and it is most important that it includes fields such as experimental and cognitive philosophy. But in this context I would also like to relativize Silius' belief that the biggest incentive for diversification of academic philosophy will not come from the discovery or creation of theoretical grounds, but rather from the intensified practice of actual philosophizing. Perhaps both, the theoretical grounds and the practical philosophizing, are equally important and have to function in a mutually complementary fashion.

Nevertheless, the article is most significant precisely because it raises questions linked to intercultural or transcultural philosophy in the context of its academic institutionalization. The author addresses this problem from several different, albeit interconnected, aspects. This is important, for in spite of many critiques and discussions led by scholars and students working in the respective field of research, and even by the wider public, it has still not been satisfactorily resolved. Hence, the last thing I intend to do with my questioning of certain aspects of his presumptions is to diminish the significance and value of Silius' analysis. On the contrary, even those parts in which I cannot agree with his opinion are still highly inspirational and therefore valuable.

Among others, this also applies to the supposition, which lies in the core of his critique of the current situation in academic philosophy, and with which I cannot completely agree. Vytis Silius claims that "at the contemporary university the dominant mode of teaching philosophy at undergraduate and graduate levels takes history of philosophy as the main framework of teaching philosophy" (Silius 2020,260). This does not apply to my own university and nor to several other universities I collaborate with. Philosophy is mainly taught through its sub-disciplines and topics. Hence, I think we have to strongly relativize this assumption. To my knowledge, the history of philosophy is just one topic among many others, even though I think it is also an important ideational background, which helps the students to rationally structure their knowledge on particular contents and currents, concepts and categories. Hence, I think (and I am sure that Vytis Silius would agree with me on this point) that the history of philosophy as such should also be "globalized". As the author himself acknowledges, the ideational history is an introductory step in the process of acquiring philosophical knowledge. This must not necessarily change. What has to change, 
though, is the scope and very structure of this historical discourse. It has to be cleansed of its racist foundations, deconstructed and re-structured by re-including the Asian, Indian and Arabic pioneers of written philosophy, and by weaving into its fabric other, hitherto unknown thinkers. Therefore, I also cannot agree with Silius' presumption that the reason for the Orientalist and Eurocentric nature of traditional comparative philosophy as a field of academic research lies in its reliance on the history of philosophy as the main mode of teaching and researching. Besides, I am convinced that for philosophy its history is equally important, as it is for the integral distinctiveness of every human being, and every society. History, of course, is history only because it has to function in and serve the societies it is written for and the people who live in them. Therefore, as Vytis Silius claims, "historical and cultural contextualization, which can be adequately achieved only through a rigid study of the history of ideas ... has to be complemented by actual reconstruction, reinvention, and reformulation of the inherited philosophical classifications and technical philosophical terminologies" (Silius 2020, 267). However, with regard to the non-European philosophies there is also another important foundation which has to be mastered, for it is indispensable for their proper and coherent understanding, namely their underlying methodologies which include frameworks of reference or paradigmatic networks (Rošker 2015, 56-62) that have to be learned in order to allow an adequate understanding.

In Silius's view, another important reason for the prejudices linked to Chinese philosophy as an academic discipline lies in the colonial tradition of Sinologists, who were the first transmitters of Chinese thought to the Western world. In his view, most of these scholars did not identify themselves as philosophers, and therefore, such research "did not have the 'universalistic thrust' characteristic and indispensable for philosophy, and it did not attempt to challenge and change Eurocentric orientation of academic philosophy" (Silius 2020, 265). I think that we ought to be careful when evaluating the contributions of such pioneers of intercultural mediation. Even though for many of them this accusation holds true, we cannot overgeneralize these aspects, for in spite of their non-reflective nature and the lack of any proper methodology, numerous Sinologists have made great contributions not only by translating and introducing Chinese philosophy to Western audiences, but also by providing the first innovative analyses and interpretations of the crucial works. ${ }^{8}$ Their emphasis on language and linguistic structures does not always necessarily imply the neglecting of philosophical questions. On the contrary, it was often more than valuable for

8 Alfred Forke and Wolfgang Bauer, for instance, have contributed many valuable insights into the genuine nature of Chinese philosophy, even though they were Sinologists. 
obtaining a thorough and more autochthonous understanding of specific concepts, categories and specific paradigms that cannot be found in Western (nor the alleged "universal") philosophy.

Because I don't want this reply to become longer than the article to which it refers, I will abstain from discussing the numerous interesting methodological questions raised by Vytis Silius with regard to (intercultural) comparative philosophy. His study provides a brilliant analysis and coherent critique of the traditional comparative methods in intercultural philosophy, summarizing all alternative approaches (such as the philosophy of fusion, or post-comparative philosophy ${ }^{9}$ ) under the umbrella term "postcomparative philosophy". Such a philosophy should, in his view, surpass the narrow boundaries of the "correct exposition" of philosophical views and positions we already know of. It could thus overcome the limitations of "seemingly static and historically settled philosophical cultures, traditions, thinkers, texts, and concepts" (Silius 2020, 270). It could furthermore offer us new ways of using ideas and views from all over the world as inspirations for our own philosophizing, and allow us to solve "hitherto unsolved problems possibly raising issues never raised before anywhere" (Chakrabarti and Weber 2016, 22). Irrespective of the fact that by constructing the term "postcomparative" Silius has made a somewhat unlucky choice ${ }^{10}$, his ideas developed under this title are very significant and more than worthy of our exhaustive consideration.

In this context, his elaborations on the future possibilities of transcultural philosophy are especially valuable. Silius exposes the importance of transcultural studies, and elaborates in detail on its future possibilities. Even though he also laments that, unfortunately, "the term transcultural (transculturality) is virtually absent from philosophical-including comparative philosophy_discourse” (Silius 2020, 273), this is not entirely true. Transcultural philosophy is a long-standing discourse, though one with continuously changing and developing paradigms. Transcultural philosophy has been an important field of philosophical investigation for at least half a century, starting with Eduardo Valera's construction of its methodological bases (Valera 1972a; 1972b), and developing further more or less continuously in the decades since (see for instance Fredericks 1988; Nielsen 1995; Siegel 1999;

9 See Chakrabarti and Weber 2016, and Moeller 2018.

10 Similar to the original term "post-comparative", its modification into the single compound "postcomparative" is likewise problematic. These terms say nothing except that we are dealing here with something which comes after the era of the domination of comparative methods. It does not say anything about the concrete ways of these new methods, nor about the reasons for the elimination of comparative approaches. Besides, such terms are problematic because of the open and all-encompassing relativization of reality and the methods of its interpretation. In this sense, they are similar to the term post-modernist. 
Wang 2002; 2020; Rošker 2005; Hashi 2007; 2016; Obert 2011; Heubel 2011; 2019; Lee 2013; Pajin 2015; Bartosch 2017; Dai 2020 and many others).

Last, but not least, I would like to point to the highly interesting fact that transcultural studies proceed from a framework of reference which is very similar to the one defining traditional Chinese philosophy. This means that Chinese philosophy can provide much more solid bases for transcultural philosophizing than its Western counterpart. This is not surprising, for-similar to transcultural philosophy, classical Chinese philosophical discourses are also rooted in a dynamic relational onto-epistemology, which does not operate with essential concepts that lead to the notion of "being". If we therefore aim to apply the basic paradigms of transcultural studies to Chinese-Western intercultural philosophy, we might achieve better (and more "objective") results if we start from the Chinese, instead of the Western model, because dynamic representations can integrate the static ones, but not vice versa. Only in this way can philosophizing across borders, languages and horizons be intensified and gradually reach the point of a Kuhnian paradigmatic shift. This brings us back to another consideration, which is above all linked to the question of existing power relations in the contemporary world.

It is not enough to simply state that a new transcultural philosophy is necessary. In order to work towards the best possible interaction and syntheses among diverse philosophical traditions, insights and approaches, we need to ask ourselves about the reasons that are lurking behind such endeavors. In other words: diversification of different philosophical approaches and methodologies is not only unavoidable due to the increasingly intensive existing practices of contemporary active philosophers (Silius 2020,277). These practices—as all practices-are chiefly a result of the present state of the present global situation. What is more important is the purpose, or the final cause of these practices, the origin of which lies in the fact that the global economy, global politics, and the network of corresponding modes of communications (including academic ones) necessitate new approaches for explaining reality. A diversified approach is not only the most "democratic" one, but also the one that allows us to gain genuinely new insights and further develop existing theoretical paradigms. However, what needs to be considered in this respect is also the question of whether these new (and doubtless more "democratic") trends are not—inter alia —also linked to the fact that today global economic and political power is being transferred from the Euro-American to the East Asian region. Let us hope that the so-called "New Type of Great Power Relations" that has been established in the framework of such developments will allow us to create a more equal, less violent and less biased paradigm of intercultural philosophical dialogues. In my view, this is precisely the main agenda of our future work, and also the main message of Vytis Silius' article. I sincerely hope that this remarkable 
paper will represent the beginning of new, topical and important debates on the theme, and one of the first steps on the long and winding road leading towards a new Politeia of transcultural philosophies.

\section{References}

Bartosch, David. 2017. "Explicit and Implicit Aspects of Confucian Education." Asian Studies 5 (2): 87-112.

Chakrabarti, Arindam, and Ralph Weber. 2016. "Introduction." In Comparative Philosophy without Borders, edited by Arindam Chakrabarti, and Ralph Weber, 1-33. London: Bloomsbury.

Dai, Yuanfang, ed. 2020. Transcultural Feminist Philosophy: Rethinking Difference and Solidarity Through Chinese-American Encounters. Lanham: Lexington Books.

Defoort, Carine. 2001. "Is There such a Thing as Chinese Philosophy? Arguments of an Implicit Debate." Philosophy East and West 51 (3): 393-413.

Fredericks, James. 1988. "The Kyoto School: Modern Buddhist Philosophy and the Search for a Transcultural Theology." Horizons 15 (2): 299-315. doi:10.1017/S0360966900039177.

Hashi, Hisaki. 2007. Komparative Philosophie der Gegenwart: Transkulturelles Denken im Zeitalter der Globalisierung. Wien: Passagen Verlag.

—. 2016. "The Significance of "Mushin": The Essential Mind of Zen Buddhist Philosophy for Humans in a Contemporary World." Asian Studies 4 (1): 97-112.

Heubel, Fabian. 2011. "Kant and Transcultural Critique: Toward a Contemporary Philosophy of Self-Cultivation." Journal of Chinese Philosophy 38 (4): 584-601.

—. 2019. "Beyond Murderous Dialectics: On Paradoxical Thinking and Maoism." Asian Studies 7 (1): 37-54.

Lee, Ming-huei. 2013. Konfuzianischer Humanismus - Transkulturelle Kontexte. Bielefeld: Transcript Verlag.

Moeller, Hans-Georg. 2018. "On Comparative and Post-Comparative Philosophy." In Appreciating the Chinese Difference: Engaging Roger T. Ames on Methods, Issues, and Roles, edited by Jim Behuniak, 31-45. Albany: State University of New York Press.

Nielsen, Greg. 1995. "Bakhtin and Habermas: Toward a Transcultural Ethics." Theory and Society 24 (6): 803-35.

Obert, Mathias. 2011. "Transformative Phenomenology and Transcultural Philosophical Thinking." Zhengzhi daxue yhexue xuebao (National Chengchi University, Philosophical Journal) 25 (1): 47-68. 
Pajin, Dušan. 2015. "Comparative Philosophy. An Evolution in Understanding History of Philosophy." Arche 8 (15): 25-55.

Raud, Rein. 2006. "Philosophies versus Philosophy: In Defense of a Flexible Definition." Philosophy East and West 56 (4): 618-25.

Rošker, Jana S. 2005. Na ozki brvi razumevanja: medkulturna metodologija v sinoloških študijah. Ljubljana: Filozofska fakulteta.

—. 2015. "Intercultural Methodology in Researching Chinese Philosophy." Zhexue yu wenhua yuekan 42 (3): 55-76.

-. 2020. Becoming Human: Li Zehou's Ethics. Leiden, Boston: Brill.

Said, Edward. 1979. Orientalism: Western Conceptions of the Orient. New York: Vintage Books.

Siegel, Harvey. 1999. "Multiculturalism and the Possibility of Transcultural Educational and Philosophical Ideals." Philosophy 74 (3): 387-409. doi:10.1017/ S0031819199000467.

Silius, Vytis. 2020. "Diversifying Academic Philosophy: The Post-Comparative Turn and Transculturalism." Asian Studies 8 (2): 257-80.

Valera, Eduardo Pérez J. 1972a. “Toward a Transcultural Philosophy (I).” Monumenta Nipponica 27 (1): 39-64.

—. 1972b. "Toward a Transcultural Philosophy (II)." Monumenta Nipponica 27 (2): 175-89.

Wang, Keping 王柯平. 2002. 走向跨文化美学 (Towards A Transcultural Aesthetics). Beijing: Zhonghua shuju.

—. 2020. "Behind Harmony and Justice." Asian Studies 8 (1): 101-25.

Xiang, Shuchen. 2019. "Why the Confucians Had no Concept of Race (Part I): The Antiessentialist Cultural Understanding of Self." Philosophy Compass. https://doi.org/10.1111/phc3.12628. 